\title{
Concepts of Emission Reduction in Fluidized Bed Combustion of Biomass
}

\author{
Amon Purgar ${ }^{1}$, Franz Winter ${ }^{1}$ \\ ${ }^{1}$ Vienna University of Technology, Institute of Chemical Engineering, Getreidemarkt 9/166, 1060 Vienna, Austria \\ Correspondence to: amon.purgar@tuwien.ac.at
}

\begin{abstract}
A status report on fluidized bed technology in Austria is under preparation, in response to the Fluidized Bed Conversion multi-lateral technology initiative of the International Energy Agency. This status report focuses on the current operation of fluidized bed combustors. Combustors have been installed in the following industrial sectors: pulp and paper, biomass heat and power plants, waste-to-energy plants, and communal sewage sludge treatment plants. There are also some small demonstration plants. These plants all have in common that they treat renewable fuel types. In many cases, only bio-fuels are treated. Besides the ability to burn a wide range of low-grade and difficult fuels, fluidized bed combustors have the advantages of low $\mathrm{NO}_{\mathrm{X}}$ emissions and the possibility of in-process capture of $\mathrm{SO}_{2}$. Various emission reduction concepts for fluidized bed combustors that are typical for their industrial sector are discussed. The discussion of these concepts focuses on $\mathrm{NO}_{\mathrm{X}}, \mathrm{SO}_{2}$ and dust.
\end{abstract}

Keywords: fluidized bed combustion, emission reduction systems.

\section{Fluidized bed combustion}

The history of fluidized bed conversion is considered to have started in about 1920. A name linked to the development of fluidized bed conversion is Fritz Winkler, who conducted flue gas into the bottom of a vessel containing coke particles. When the volume flow of the flue gas increased, the phenomenon of fluidization could be observed. The bulk coke increased in volume, and Winkler observed that the motion of the coke particles was similar to that of a boiling liquid. This application can be described as fluidized bed gasification. He patented his findings in 1922, and continued building and investigating fluidized bed applications. The first boom in the commercial use of fluidized bed conversion was in the 1930 s and 1940s. The reason for this boom is easy to explain: air blowers became commercially available at that time. Further information about the history of fluidized bed conversion can be found in [1]. It should also be mentioned that, at least in Austria, there was also a big increase in fluidized bed combustion applications between 1980 and 1993 in the pulp and paper industry. Another increase in fluidized bed combustion technology in the waste-toenergy industry began in 2000, and is still going on. The reasons for these booms and their relationship to flue gas cleaning will be discussed below.

There are two main concepts: bubbling and circulating fluidized bed combustors. The two concepts are illustrated in Figure 1. Fluidized bed combustors mainly consist of a vessel containing a gas distributor, the bulk bed material and the freeboard. The gas distributor, overlaid with the bed material, leads the fluidization air into the vessel. It flows through the bed material, and fluidization takes place. Gas distributors can be open or closed. If a closed gas distributor is built, all the bed material is above the distributor. If the distributor is open, the bed material is situated around the distributor.

The bulk bed material consists mainly of inert sand, in most cases silica or dolomite. At standstill the vessel is not entirely filled with bed material. It is filled to a height considering expansion due to fluidization. The empty space at the top of the vessel is called the freeboard. If the combustor is not equipped with an air staging system, the fluidization air is the entire combustion air. If there is an air staging system, the fluidization air is the primary air, possibly mixed with recirculated flue gas, and the secondary air is injected above the fluidized bed. The fluidized bed is heated to a certain temperature before the fuel supply is started. For this purpose, most fluidized bed combustors are equipped with a gas burner for the start up. Once the fluidized bed material is at the required temperature, the fuel is injected and due to the horizontal and vertical movement of the bed material the fuel is well mixed into it. The excellent mixing behavior and the high heat capacity of the sand, which acts as a mobile heat tank, ensure an even temperature and even fuel distribution in the combustion chamber. In addition, the overall tem- 


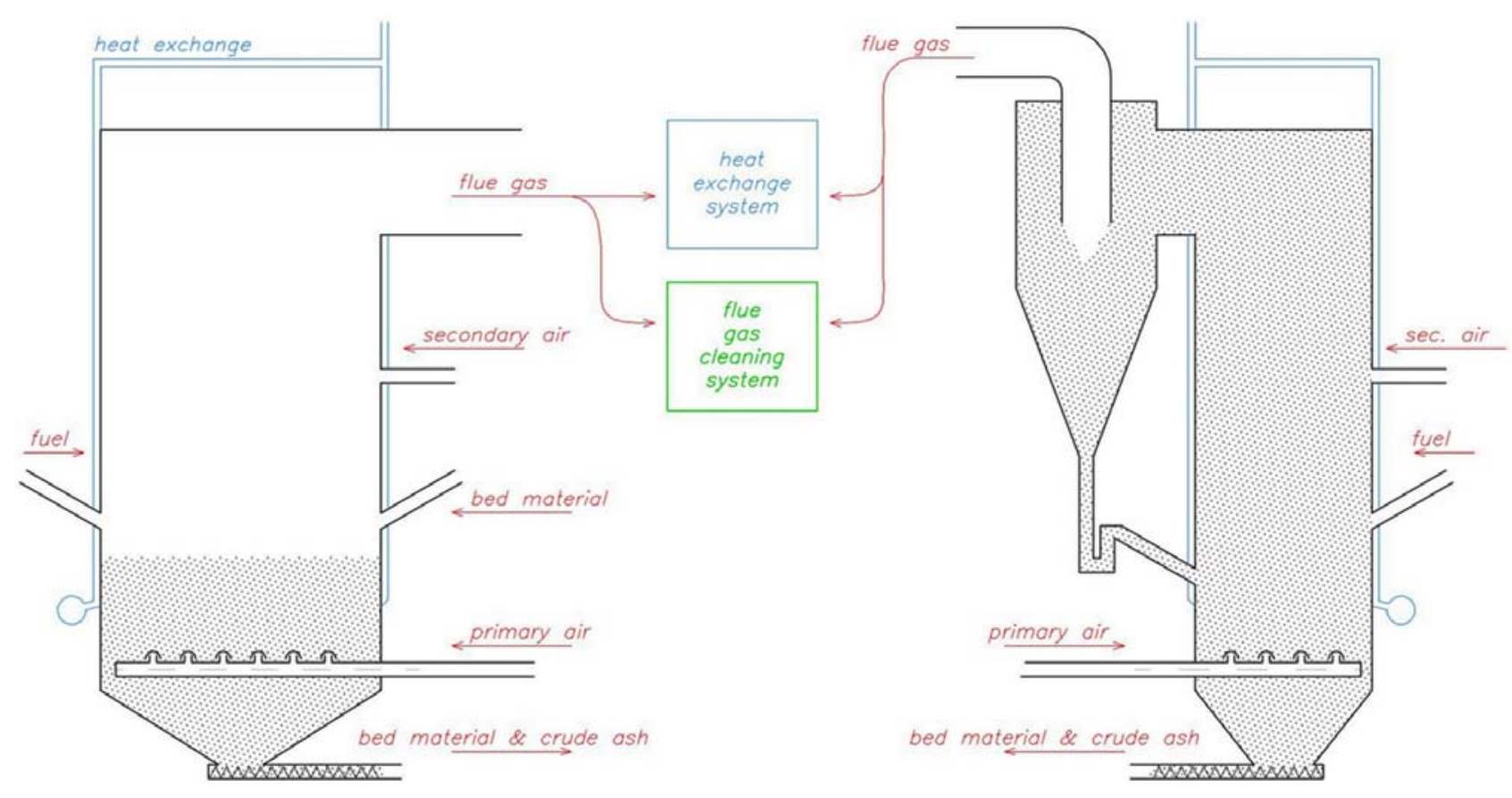

Figure 1: Basic functionality of a fluidized bed combustor. Left: A bubbling fluidized bed combustor. Right: A circulating fluidized bed combustor

perature in the combustion chamber is very insensitive to fuel quality fluctuations over time. These stable temperature conditions and the possibility of in process capture of $\mathrm{SO}_{2}$, when limestone is used as an additive, are the main advantages over grate furnaces and pulverized combustors. [4]

Besides the enhanced constructional effort, fluidized bed combustion technology has two main limitations. Depending on the ash composition, the maximum temperature in the fluidized bed is limited. When the ash melting point is reached there is a possibility of agglomeration within the bed material, which can reduce or stop fluidization. In addition, the superficial velocity within the reactor, depending on the fluidization air flow and the cross sectional area, must be above the minimum fluidization velocity, that ensures fluidization, and below the terminal velocity, which is the minimum velocity in the pneumatic transport regime. $[1,4]$

\section{Fluidized bed combustors in Austria}

A status report on fluidized bed technology in Austria is under preparation, in response to the Fluidized Bed Conversion multi-lateral technology initiative of the International Energy Agency. This status report focuses on the current operation of fluidized bed combustors. Besides two demonstration plants and other fluidized bed conversion plants, 23 fluidized bed combustors with a thermal capacity of more than $1 \mathrm{MW}$ were found and investigated. The 23 combustors were categorized into the following four industrial sectors, how, is described in the following enumeration:

- Pulp and Paper. Combustors which supply a pulp and paper plant with energy and do not utilize municipal wastes.

- Waste-to-Energy Industry. Combustors that utilize municipal wastes.

- Biomass Heat and Power plants. Combustors that utilize only renewable fuels and are not connected to the pulp and paper industry.

- Treatment of Communal Sewage Sludge. Combustors utilizing only communal sewage sludge.

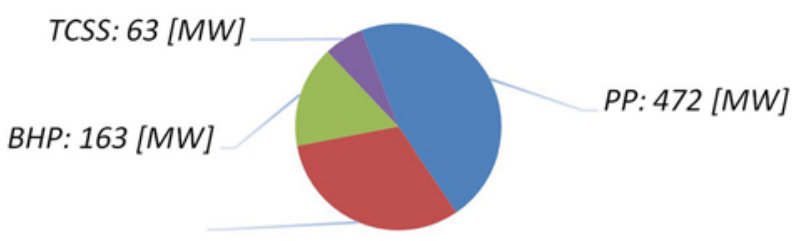

WTE: 321 [MW]

Figure 2: Total thermal capacity of fluidized bed combustors installed in the pulp \& paper (PP), waste-to-energy (WTE), biomass heating and power plants (BHP), and treatment of communal sewage sludge (TCSS) industrial sectors 


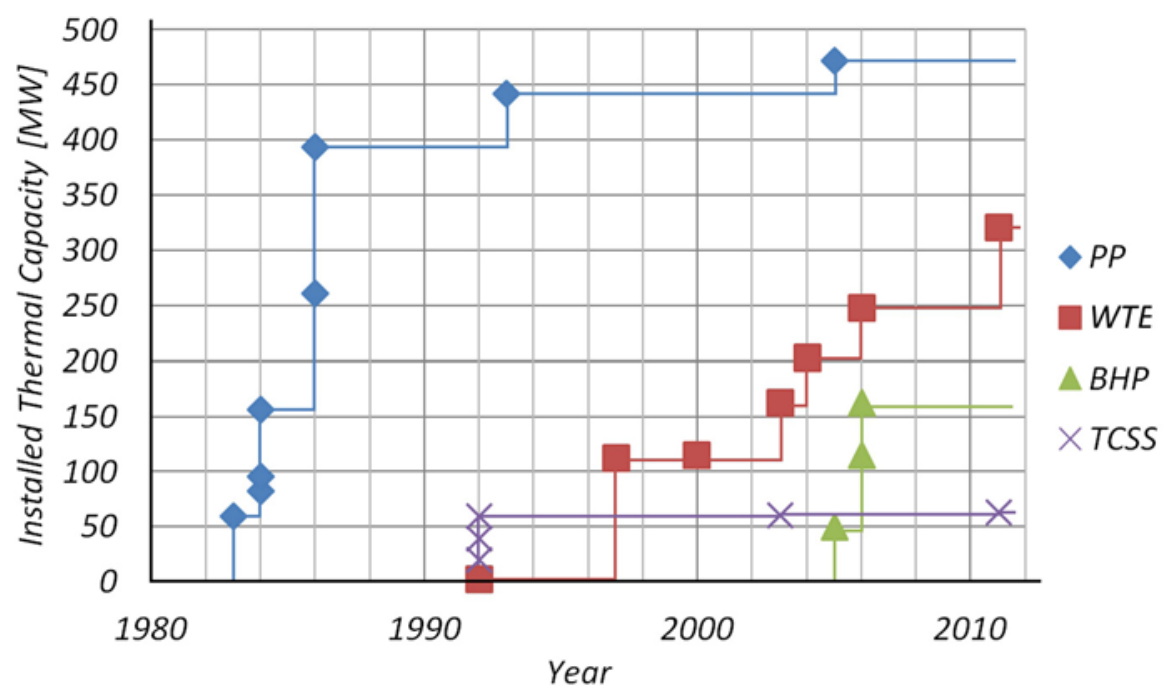

Figure 3: Thermal capacity of fluidized bed combustors installed in the pulp \& paper (PP), waste-to-energy (WTE), biomass heat and power plants (BHP) and treatment of communal sewage sludge (TCSS) industrial sectors, over time

Table 1: Hourly and daily emission standards for the investigated plants in the waste-to-energy industry [5,6]

\begin{tabular}{|l|c|c|c|c|c|}
\hline & Dust $\left(\mathrm{mg} / \mathrm{m}^{3}\right)$ & $\mathrm{C}_{\text {org }}\left(\mathrm{mg} / \mathrm{m}^{3}\right)$ & $\mathrm{SO}_{2}\left(\mathrm{mg} / \mathrm{m}^{3}\right)$ & $\mathrm{NO}_{X}\left(\mathrm{mg} / \mathrm{m}^{3}\right)$ & $\mathrm{CO}\left(\mathrm{mg} / \mathrm{m}^{3}\right)$ \\
\hline minimum & $5 / 5$ & $8 / 8$ & $20 / 20$ & $60 / 55$ & $50 / 50$ \\
\hline maximum & $10 / 10$ & $10 / 10$ & $50 / 50$ & $100 / 70$ & $100 / 50$ \\
\hline average & $7.75 / 7.75$ & $8.5 / 8.5$ & $40 / 37.5$ & $75 / 66.3$ & $75 / 50$ \\
\hline
\end{tabular}

\section{The influence of flue gas cleaning}

Pulp \& Paper Industry:

Figure 3 shows that most of the fluidized bed combustors in the pulp and paper industry were installed between 1983 and 1986. Widely-used fuels are coal, biomass and fibrous rejects of the pulp and paper industry. Gas as a fuel is used only for starting up the combustors. The main purpose of these boilers is to cover the main load of the energy demand of a pulp and paper plant. The legal framework at that time required these boilers to be equipped with electrostatic precipitators or baghouse filters and, depending on the fuels that were used, it was required to be able to add bulk limestone to the combustion chamber for in-process capture of $\mathrm{SO}_{2}$. Over time, some of the boilers have additionally been equipped with a selective non-catalytic flue gas cleaning system or a dry flue gas cleaning system. $[3,6]$

Waste Incineration Industry:

At the end of 2011, there were seven fluidized bed combustors in this sector. Together they have a capacity of $321 \mathrm{MW}$. Four of these boilers, with a total thermal capacity of $268 \mathrm{MW}$, have been investigated closely. Table 1 shows that there is a strict legal framework in the waste-to-energy industry.

In order to handle those strict standards, all the investigated plants use a similar setup of flue gas treatment systems, see Figure 4. Due to tightening of the standards in recent years, this elaborate flue gas cleaning setup became necessary both for fluidized bed combustors and for grate furnaces. It should be mentioned here that standards are increasingly being set for shorter averaged sample time periods. This means that the flue gas cleaning systems are designed to handle emission peaks. For this reason, the advantage of the stable operating conditions of fluidized bed combustors has become crucial when deciding between grate furnaces and fluidized bed boilers. In 2006, there were three grate furnaces in Austria, with a total capacity of 87 tons of waste per hour, and three fluidized bed combustors, with a total capacity of 99 tons of waste per hour, in the process of planning $[2,6]$. 


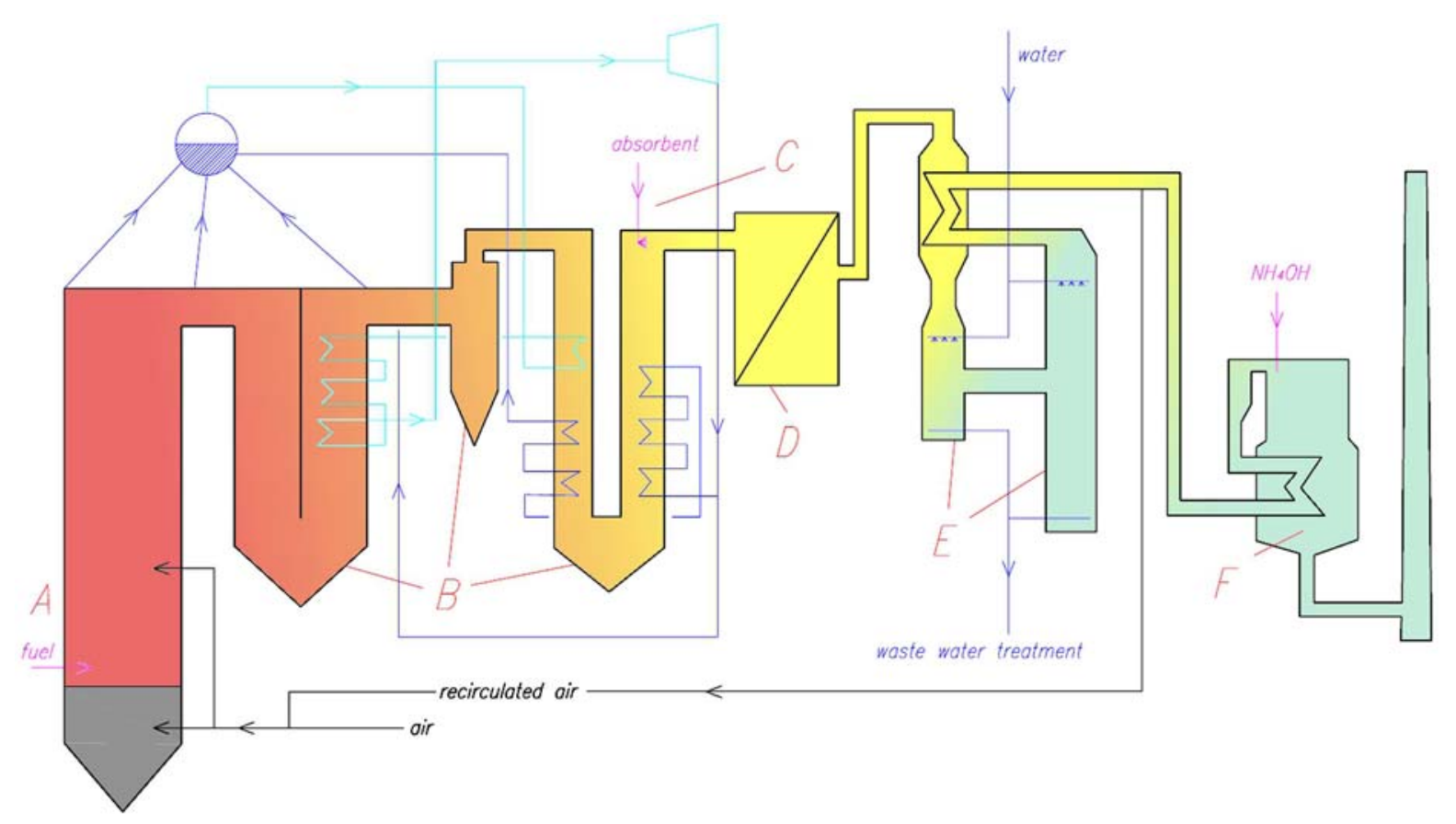

Figure 4: Basic setup of the flue gas cleaning system in the waste-to-energy industry. A) fluidized bed combustor, B) gravitation and/or centrifugal separators, C) dry flue gas cleaning, D) baghouse filter or electrostatic precipitator, E) wet scrubbers, F) selective catalytic reduction (SCR)

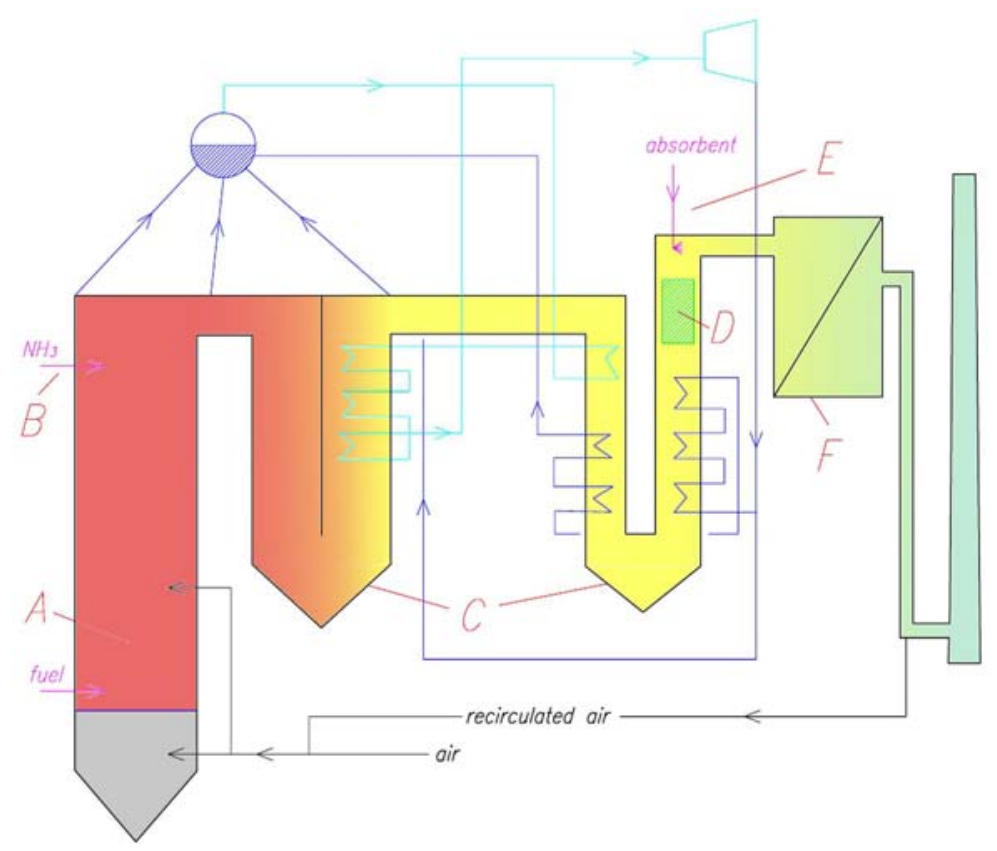

Figure 5: Basic setup of the flue gas cleaning system for biomass heat and power plants. A) fluidized bed combustor, B) selective non catalytic reduction, C) gravitation separators, D) selective catalytic reduction in high dust switching, E) dry flue gas cleaning system, F) baghouse filter

Treatment of Communal Sewage Sludge:

At the end of 2011, there were five boilers that exclusively utilize communal sewage sludge. Two of them have a thermal capacity below $2 \mathrm{MW}$ and are not discussed in this work. The other three combustors are structurally identical, and are all located in the same place. They have a thermal capacity of $20 \mathrm{MW}$ each, and have basically the same flue gas cleaning systems as those sketched in Figure 4. A notable difference is that there is a fixed bed activated carbon absorber between the wet scrubbers and the SCR. In addition, no dry flue gas cleaning system is installed [6]. 
Biomass Heating Plants:

Three fluidized bed combustors were put into operation in 2005 and 2006. Together they have a thermal capacity of $163 \mathrm{MW}$. Two of these boilers, with a thermal capacity of $116 \mathrm{MW}$, have been investigated closely. The two investigated biomass heating plants have almost the same flue gas treatment system, see Figure 5, except that one of them also has selective catalytic reduction in high-dust switching. An obvious difference from the boilers in the wasteto-energy industry is that there are no wet scrubbers. This is because of the low sulfur content of the biomass. $[6,7]$

\section{Summary}

In Austria, fluidized bed combustors are mainly used in the pulp and paper industry, in waste-to-energy plants, in biomass heat and power plants, and in communal sewage sludge treatment. Each of these industrial sectors uses a typical fuel mixture. A specific flue gas cleaning system setup is installed for the typical fuel mixture that is used.

In the pulp and paper industry, mainly baghouse filters or electrostatic precipitators are used. Some combustors also have a selective non-catalytic reduction system (SNCR) and a dry flue gas cleaning system.

In the waste-to-energy industry and in communal sewage sludge treatment, the plants are equipped with an elaborate flue gas cleaning system. This system basically contains gravitation and centrifugal separators, a dry flue gas cleaning system, baghouse filters, wet scrubbers, and a selective catalytic reduction system (SCR).

The flue gas cleaning systems of biomass heat and power plants contain gravitation and centrifugal separators, a dry flue gas cleaning system, and baghouse filters. Additionally, a selective catalytic reduction system in high-dust switching can be installed.

\section{Acknowledgement}

We would like to acknowledge the Austrian
Federal Ministry for Transport, Innovation and Technology (http://www.bmvit.gv.at) for funding the Austrian activities within the International Energy Agency Fluidized Bed Conversion Agreement (http://www.iea-fbc.org). In addition, we would like to acknowledge the support provided by the IEA - Fluidized Bed Conversion Network (http://www.iea-fbc.net).

\section{References}

[1] Winter, F., Szentannai, P.: IEA Fluidized Bed Conversion Programme, Status Report 2010, Österreichisches Bundesministerium für Verkehr, Innovation und Technologie, 2010, Vienna.

[2] Böhmer, S., Kügler, I.: Abfallverbrennung in Österreich Statusbericht 2006. Umweltbundesamt GmbH, 2007, Vienna. ISBN 3-85457-911-X.

[3] Stubenvoll, J., Holzerbauer, R.: Technische Maßnahmen zur Minderung der Staub- und $\mathrm{NO}_{x^{-}}$ Emissionen bei Wirbelschicht- und Laugenverbrennungskesseln. Umweltbundesamt GmbH, 2007, Vienna. ISBN 3-85457-837-7.

[4] Zbigniew, B.: Fluidized Beds, Handbook of Combustion Vol. 4: Solid Fuels. WILEY-VCH Verlag GmbH \& Co. KgaA, 2010, Weinheim, p. 399-433. ISBN 978-3-527-32449-1.

[5] Amon, M., Grech, H.: Bericht des Bundesministers für Land- und Forstwirtschaft, Umwelt- und Wasserwirtschaft über Verbrennungsund Mitverbrennungsanlagen gemäss $§ 18$ AVV, Berichtszeitraum 2009, Bundesministerium für Land- und Forstwirtschaft, Umwelt- und Wasserwirtschaft. 2010, Vienna.

[6] Provided Information from the IEA-Fluidized Bed Conversion Network Austria.

[7] Selcuk, N., Gogebakan, Z.: Co-Firing Biomass with Coal in Fluidized Bed Combustion Systems, Handbook of Combustion Vol. 4: Solid Fuels. WILEY-VCH Verlag GmbH \& Co. KgaA, 2010, Weinheim, p. 557-608. ISBN 978-3-527-32449-1. 